\title{
Methodology of the Comprehensive Teacher Training
}

\author{
Dzhumanova Lola \\ Moscow P. I. Tchaikovsky Conservatory, Moscow, Russia
}

\begin{abstract}
Pedagogical tradition regarding musical education in Russia is one of the country culture achievements. Arrangement of quality musical pedagogy has been a matter of special importance within half a century history of music education system forming. Training of music teachers is particularly important in the field of music theory, as the comprehensive musician training is specific for Russian music education, where besides playing a music instrument he must possess knowledge from the music theory field, make sense of music pieces, and understand and analyze them. The conservatism in teaching traditions preservation began interfering with changing priorities of education. As a result, stagnation in the field of musical pedagogy was outlined in the early XXI century. This has affected teaching music and theoretical subjects, which became heavy, boring, and unpopular due to conservatism in teaching methods and focus on students' motivation. As professional regards, there has been an imbalance in the ability to play the instrument and the inability to navigate in the music literature. Implementation of innovative approaches to teaching issues and appropriate teachers training has become a necessary solution to the problem. The report considers innovations in teachers training traditions on example of the leading musical institution Moscow Tchaikovsky Conservatory.
\end{abstract}

Keywords: pedagogical training of musicologists, comprehensive approach, innovative forms of training, multidisciplinary nature

\section{Introduction}

One of the main directions of teaching students at the Moscow P. I. Tchaikovsky Conservatory is the training of teaching staff. To date, certain traditions in the organization of future teacher training were developed. The preparation of the skilled staff is the most interesting in the historical and theoretical faculty, where not only future musicologists, journalists, and lectors are trained, but also teachers of different musical and theoretical subjects are trained, without which the complete professional musician activity is not possible. It is about solfeggio, music theory, harmony, polyphony, and musical analysis and literature. In this faculty, the best traditions of teachers training get logical addition in the form of a comprehensive methodology for pedagogical training of students, which allows getting highly professional teachers of musical and theoretical disciplines after graduation. The peculiarity of this training lies in the fact that graduates are not narrowly but widely professional staff, which competent in matters of teaching in schools and colleges. The multidisciplinary nature is the distinctive feature of students training at the present faculty.

To be noted that a conservatory being the higher stage in the system of professional music education was formed as the first one in Russia historically, thereafter due to reliance on the pre-university training lower

Dzhumanova Lola, assistant professor, Ph.D. in History of Arts, Department of Theory Music, Moscow P. I. Tchaikovsky Conservatory, Moscow, Russia. 
stages such as music schools and profession-oriented school appeared. The institution trains teachers to be capable to preserve level and traditions of musical education in Russia for these stages.

\section{The Comprehensive Approach in Stages of Students Training}

The guarantor of the quality training of future teachers is a multi-stage structure of the learning of teaching experience. Initially, it was simple and had two stages: a course of lectures on the methodology and teaching practice of teaching music theory courses. At the lectures in Methods, students have an opportunity to meet the specifics of a certain subject, finding out the existing methods for its teaching, pedagogic traditions, and educational and methodical literature for teaching a subject at different levels.

The second stage of teachers training is their direct practice, where the students have an opportunity to conduct lessons during the long period combined with the study. At this stage, the students can teach different subjects in any age group.

However, the demand for the third systematizing stage - the final qualification work, which could add up the readiness of a student to conduct quality lessons competent-arose in the course of time. The form, in which the idea of evaluation of pedagogical knowledge and skills of high school graduates embodied, was the defense of qualification work - methodological report on the problems of teaching a particular discipline.

After the successful mastering of all stages, a student is qualified as "Teacher of musical and theoretical subjects".

\section{Innovations, Which Came From the First Stage of Education}

The best traditions of teaching are always carefully treated in training process of the Moscow Conservatory. Therefore, the one plan of subjects' conduction was preserved. The lectures in Methods always remained lectures and pedagogical practice had a format of lessons with a group of pupils. This conservatism had gradually brought to a standstill and degradation of some students' training level. The realities of the modern format with the inclusion of computer training and online resources dictated the need for new approaches in the field of the students' pedagogy training. It must be admitted that in the field of music education at the professional level, a conservative approach to the introduction of modern multimedia technologies is due to the principle of motivation of those, who came to master the profession. Therefore, modern technologies are limited used in the disciplines of music.

Most of all the technological innovations in the field of music education affected the sphere of non-professional musical training (the so-called additional education), namely, children's music and art schools, where children and adolescents are engaged, who are unmotivated and who need to be interested in a long process of learning a musical instrument. The fact of free and long communication of modern children with gadgets was used by pedagogues at that stage of music education for implementing the gaming multimedia technologies into the learning process.

Paradoxically, but these examples were relevant for the modern teachers training. Therefore, the master-classes in the form of open lessons of invited skilled teachers from the lower stage of education have become the innovative form in the lectures course in Methods. The video presentations of such specialists clearly demonstrate the learning outcomes with the use of modern technologies. It is logically, that for the student getting acquainted with these technologies, the development of lessons by using multimedia becomes important, which they can defense after approbation in practice as the methodological work at the third stage of 
training-state qualification examination.

\section{Innovations in Expanding Teacher Training Format}

The updated principle of slant on the questions of teachers training also relates to going above mastering the traditional and classical disciplines. The modern musical and theoretical pedagogy introduced a range of new innovative disciplines, which are aimed at the comprehensive training of future musicians purposely combination of knowledge from different subjects for the more fundamental understanding of a music piece. In particular, such subject as Theory of music content becomes more popular. The author of this subject is the professor of the Moscow Conservatory V. N. Kholopova. This subject having arisen in the system of the higher music education quiet quickly was adopted by teachers of the primary stage of the music education. Its essence is to bring together all the knowledge obtained in different disciplines for a holistic analysis in order to understand a piece of music. As the number of specialists, who know this subject, is very small, our Conservatory fills this gap and provides an opportunity for students to practice in this discipline after previously listening of methodical lectures of the discipline author and hereafter defense the methodology project on the subject chosen within the frameworks of this discipline.

Listening to Music became another innovative subject, which had already arisen in the depths of primary music education. This subject has been coined by a teacher of children's music school N. V. Tsareva with the aim to teach children to listen, hear, and understand music. As there are not so many specialists who can teach this subject, the preparation of students to its teaching is provided. The author, who created this discipline, is invited for the methodological lecture with the video demonstration of lessons as well as for the master class in the provided group of pupils, where student can see the methodology of subject teaching in real time.

All of these updates can significantly expand the boundaries of the modern teachers training to enhance their capabilities. In its turn, this fact allows the conservatory to be sure that all of its graduates will be demanded and, consequently, employed after graduation.

\section{Innovative Forms of Student Practice}

One of important factors of the quality change of students' qualification training is the possibility of multifold participation in the training process. First of all, it is about the activation of cognitive side of the issue. The format of preliminary preparation for the upcoming practice is now added to the previous forms of lectures of a specialist in teaching certain subject. It may be related to the student's own researches in the field of pedagogy, search, and justified choice of modern teaching publications on various subjects. It can be a form of the project, the methodical elaboration of a particular discipline, its section, or topic.

The game situations become one of the usual forms of work on the preliminary preparation for the practice in the course of lectures on methodology. Here, the students are given the task to imagine themselves as a teacher of a specific subject in a particular class (the role of which performs the rest of the students group). Next, the student has to project a certain situational scene.

The discussions of the open lessons conducted by the senior students finishing practice and obtaining an estimate for pedagogical practice have become an innovative form of pedagogical professional training. A great help in organization of such views and discussions is a specially created base in the Conservatory for practice of students, the music school with a ten-year course of study, which compounds two (primary pre-professional and secondary professional) stages of education. The students, who are starting practice, have an opportunity to 
compare their impressions from the observed lesson with the opinion of other students and presenting heads of practical trainings.

\section{Conclusion}

The results of the comprehensive multifaceted approach to the issue of future teachers training speak for itself. Today, graduates of the historical and theoretical faculty join the ranks of teachers, not only of the central affiliated educational institutions: the world-famous Central Music School and the Academic Music College of the Moscow Conservatory, but also other musical educational institutions in the regions. The specificity of such teachers is their musical polyhistory and multidisciplinary training, skill of the competence approach to any format and the subject of the lesson.

\section{References}

Dzhumanova, L. (2015). The comprehensive training as a method for optimizing the musical-theoretical subjects in children music schools/children schools of arts (pp. 5-7). Materials of the scientific-practical conference "Place and role of theoretical subjects in contemporary art education", Tomsk.

Kholopova, V. N. (2002). Special and non-special musical content. Moscow: Moscow Conservatory Press.

Moscow State Conservatory. (2009). How to teach solfeggio in XXI century. Moscow: Classic-XXI.

Tsareva, N. A. (2013). Lessons of Mrs. Melody Textbook of methods. Moscow: Presto. 